This item was submitted to Loughborough's Research Repository by the author.

Items in Figshare are protected by copyright, with all rights reserved, unless otherwise indicated.

\title{
Effects of a physical activity program on post-bariatric patients: A qualitative study from a self-determination theory perspective
}

\section{PLEASE CITE THE PUBLISHED VERSION}

https://doi.org/10.1177/1359105318770729

\section{PUBLISHER}

SAGE Publications $@$ The Authors

VERSION

AM (Accepted Manuscript)

\section{PUBLISHER STATEMENT}

This work is made available according to the conditions of the Creative Commons Attribution-NonCommercialNoDerivatives 4.0 International (CC BY-NC-ND 4.0) licence. Full details of this licence are available at: https://creativecommons.org/licenses/by-nc-nd/4.0/

\section{LICENCE}

CC BY-NC-ND 4.0

\section{REPOSITORY RECORD}

Gonzalez-Cutre, David, Angel Megias, Vicente J. Beltran-Carrillo, Eduardo Cervello, and Christopher Spray. 2018. "Effects of a Physical Activity Program on Post-bariatric Patients: A Qualitative Study from a Selfdetermination Theory Perspective". Loughborough University. https://hdl.handle.net/2134/33176. 
Effects of a physical activity program on post-bariatric patients: A qualitative study from a self-determination theory perspective 


\begin{abstract}
This study provides an in-depth analysis of the psychosocial benefits that 10 postbariatric patients (nine female, 31-59 years) perceived from their participation in an exercise program grounded in self-determination theory. Qualitative data were collected through observations and interviews. Participants reported many factors which facilitated basic psychological need satisfaction such as the instructors caring about their opinion, affection, fitness improvement, pain reduction, and knowledge acquisition. These factors were associated with autonomous motivation, enjoyment, intention to be physically active, happiness and self-confidence. The results suggest that self-determination theory-based exercise programs could be designed to achieve positive outcomes in this population.
\end{abstract}

\title{
Keywords
}

Morbid obesity, bariatric surgery, exercise, autonomous motivation, well-being 


\section{Introduction}

Morbid obesity is defined as a body mass index (BMI) greater than or equal to 40 $\mathrm{kg} / \mathrm{m}^{2}$ (World Health Organization, 2017), and constitutes a chronic stressful condition, with a number of associated comorbidities that greatly handicap individuals in their daily life (Sirtori et al., 2012). When non-invasive methods such as diet or physical activity (PA) fail, bariatric surgery has been shown to be an effective treatment for weight loss, improvement of comorbidities (Jacobi et al., 2011; Moya et al., 2014), and better psychosocial functioning (Jiménez-Loaisa et al., 2015; Sarwer et al., 2008; van Hout et al., 2006). Exercise recommendations are common after bariatric surgery as a large number of studies show positive associations between PA and postoperative weight loss (Bond et al., 2008; Livhits et al., 2010; Moya et al., 2014), overall mental health-related quality of life (Bond et al., 2008; Forbush et al., 2011) and better psychosocial outcomes (Jiménez-Loaisa et al., 2015; Rosenberger et al., 2011).

Despite these benefits, there are no standardized guidelines for the most appropriate exercise regime (Livhits et al., 2010; Moya et al., 2014) or evidence-based psychosocial guidelines to help these patients make a long-lasting behavioral change concerning PA (Peacock and Zizzi, 2011). In addition, motivating this population to participate in PA can be especially difficult (Elkins et al., 2005; Livhits et al., 2010; Zabatiero et al., 2016) and it should be an important goal after surgery, particularly in the long term when the effect of bariatric surgery itself stops being effective (Moya et al., 2014) and high rates of weight regain have been found (Magro et al., 2008).

In this sense, self-determination theory (SDT; Deci and Ryan, 2000) has demonstrated efficacy in explaining the motivational processes underlying exercise and PA behavior (e.g., Teixeira et al., 2012a; Teixeira et al., 2012b; Wilson et al., 2008). In fact, several intervention studies in exercise and PA settings grounded in SDT (e.g., 
Fortier et al., 2012; Ntoumanis et al., 2017) have successfully applied motivational strategies in different populations to achieve positive outcomes such as autonomous motivation, weight loss, and PA engagement. SDT seems to be an informative, overarching framework to translate theory into practice (Hancox et al., 2018) if we have in mind the exercisers' basic psychological needs (BPN) in the design of PA programs.

SDT is an organismic-dialectical theory of human motivation based on the premise that individuals are active in their pursuit to satisfy three basic and universal psychological needs for autonomy, competence, and relatedness. Autonomy refers to the need to be the origin of our actions, to have control over and endorse our own behavior and to make our own decisions. Competence describes the need to feel effective in ongoing interactions with the social environment. Finally, relatedness refers to the need to feel connected to people, to establish good social relationships, and to feel that people respect and value you.

If bariatric patients satisfy their BPN while participating in PA, they will develop more autonomous forms of motivation. More specifically, patients would enjoy the activity (intrinsic motivation), they would integrate it in their lifestyle (integrated regulation), and they would realize that PA is important because of its associated benefits (identified regulation). On the other hand, if BPN are frustrated, the patients would acquire more controlled forms of motivation (introjected and external regulations) or amotivation. Introjected regulation reflects participation in PA with a sense of internal obligation, avoiding feelings of guilty, while external regulation refers to participation based on obtaining external incentives or avoiding punishments, such as the recrimination of others for not being involved in healthy behaviors. Amotivation represents a lack of motivation and interest in the activity. Need satisfaction and 
autonomous motivation during a PA program would contribute to better psychosocial and behavioral effects (Ryan and Deci, 2017).

Specifically, PA literature (see Vallerand, 2007 for a review) has shown that a need-supportive environment which satisfies BPN promotes exercisers’ autonomous motivation, and this type of motivation is related to a range of positive outcomes: 1) Affective: positive affect, vitality, self-esteem, and enjoyment; 2) Cognitive: quantity and quality of concentration, and flow state; 3) Behavioral: effort, persistence, performance, and exercise adherence. Moreover, PA could have positive consequences at a global level, fostering psychological adjustment, less perceived pressure from society, and lower conflicts across life domains (Vallerand, 2007). A need-supportive style is characterized by encouraging initiative, allowing participation in decision making and offering choices, communicating the expectations and guidelines clearly, providing meaningful explanations for task-engagement and participants’ requests, acknowledging negative feelings, using an informational (rather than pressuring) language, giving specific and constructive feedback, and showing affection and taking personal interest in the participants (Leenknecht et al., 2017; Ntoumanis et al., 2017).

A qualitative methodological approach was adopted in the present study to comprehensively understand how a PA program based on SDT principles facilitated participants' BPN satisfaction, autonomous exercise motivation and adaptive outcomes in a post-bariatric sample. Qualitative evaluations of SDT-based interventions in PA settings are scarce and very recent. Different studies have tested the effectiveness of interventions to promote PA in adolescents (Sebire et al., 2016a; Sebire et al., 2016b), adults (Kinnafick et al., 2014), older adults (Lee et al., 2016; Thøgersen-Ntoumani et al., 2017), indoor cycling exercisers (Hancox et al., 2018), and in a weight management program for overweight/obese men (Donnachie et al., 2017). Some of these studies were 
qualitative and others employed a mixed-methods design, but all attempted to deepen, through interviews/focus groups with teachers/instructors and/or exercisers, understanding of how interventions promoted the satisfaction of BPN and autonomous motivation for PA. However, the present study is the first to qualitatively analyze the experience of bariatric patients participating in a SDT-based PA motivational program. This qualitative approach will help to devise strategies for the design of future PA programs which facilitate BPN satisfaction, exercise adherence, and well-being in this population.

\section{Method}

\section{Participants}

The participants were 10 morbidly obese patients (nine women) aged between 31 and 59 years $(M=45.90, S D=9.25)$, who had previously undergone bariatric surgery. One month after surgery, the participants were recruited by their clinical psychologist and were enrolled onto a 6-month PA program.

\section{Procedure and data collection}

The PA program took place in a public fitness center located on the first author’s university campus. The program consisted of two sessions per week during the first two months, three sessions per week during the intermediate two months, and four sessions per week during the last two months, each lasting one hour and 30 minutes. The program combined two different sessions; 1) Sessions with machines for the development of cardiorespiratory endurance and muscular strength; 2) Sessions not only designed to improve physical fitness, but also to introduce novelty, avoid routine, and enhance the psychosocial benefits of the PA program. These sessions included: games, directed activities (aerobic, spinning, etc), dance, aquatic training in the pool and the 
beach, body expression, quotidian materials circuit (e.g., full bottles to improve strength), core-training, and trekking.

The instructors were sport science professionals, with a Master's degree in physical activity and health. All were trained in SDT-based strategies, focused on the satisfaction of needs for competence, autonomy and relatedness during the sessions. Training was divided into two parts. The first part consisted of a 10-hour theoretical and practical seminar about motivational strategies in exercise. In the second part (2 months long), the instructors applied these strategies in a real-world context and an external observer, expert in SDT, rated their compliance with the strategies using an observation sheet for a total of four sessions. Feedback was then provided to the instructors to improve their need-supportive style.

The project was approved by the ethical research board of the first author's university. Participants were informed about the procedure and each patient provided written consent. As the study was focused on information which was personal and private or contained evaluations of other people, the participants' anonymity was protected through the use of pseudonyms. The field work was conducted by three members of the research group. Two different techniques were used to gather qualitative information. First, the director of the research project and the instructor of the PA program took chronologically organized field notes about observed conversations or situations which might be of interest in relation to the aim of the study. This information was written in their research diaries over the course of the 6-month PA program. Second, at the end of the PA program, a third researcher conducted and recorded an in-depth semi-structured interview with each participant. The interviews lasted between 40 and 60 minutes and were conducted by the same researcher for consistency. 


\title{
Data analysis
}

The field notes and semi-structured interviews were transcribed and analyzed with the support of NVivo in order to organize and classify data efficiently (Bazeley and Jackson, 2013). One member of the research group led the analysis, while the other members of the research group supervised this process and resolved discrepancies in coding or in the identification of emergent categories. These supervision meetings enhanced the quality of the coding and categorization process (Shenton, 2004).

Analysis combined strategies of both “directed” (deductive) and “conventional” (inductive) content analysis (Hsieh and Shannon, 2005). Having read the transcriptions, a map of interrelated categories and subcategories was created in accordance with SDT. The exact words from the text that captured key thoughts or concepts related to the following pre-established categories were all classified: PA program characteristics that may satisfy the needs for autonomy, competence, and relatedness; exercise autonomous motivation; and affective, cognitive, and behavioral consequences. This categorized information was subsequently analyzed inductively to identify concrete subcategories. On completion of the categorization process, categorical refinement was conducted to readjust previously identified categories, subcategories, and their contents. During this process some categories were restructured: cognitive, affective and behavioral consequences were combined into one category only. Moreover, not only contextual (PA), but global (life) consequences were included in the "consequences" category. These adjustments to the classification facilitated the interpretation of the data. The final categorical system (see Table 1) underpins the study findings presented below.

\author{
[Insert Table 1 here]
}

\section{Results and discussion}

Physical activity program characteristics and BPN satisfaction 
Caring about their opinion and preferences. Participants felt that people in charge of the PA program favored a positive feeling of autonomy, because they were allowed to take some decisions regarding the sort of exercises, the machines, the music and even the attendance schedule:

... you have worried about the opinion of all of us. You have always offered options to choose... If we wanted to do this or that... or if we preferred any sort of music (Alice' interview).

Instructors with a democratic and positive disposition. According to the participants' comments, instructors showed at any moment a suggesting, more than an imposing, disposition. Instructors also interacted with participants with a positive mood during the sessions, giving positive feedback to enhance autonomous motivation (Hancox et al., 2018):

I think that instructors should be like the ones we have here, because if you are getting pressured at the end you get tired and bored, because you say: "fuck, do I have to stand this guy?” In general [in the PA program], everybody tells you: “you can do it this way or this other way”, but they don’t impose or oblige you. It is harder to carry out imposed things than if you get an explanation of the goals with a good mood (Alice’ interview).

Both themes facilitated better relationships, but also promoted the feeling of choice and volition, thanks to the instructor's autonomy-support behavior, providing greater autonomy perceptions during the sessions which can result in more positive outcomes (Edmunds et al., 2007; Ntoumanis et al., 2017; Silva et al., 2011; Silva et al., 2010a; Silva et al., 2010b; Teixeira et al., 2012a).

Acquiring knowledge for being autonomous exercisers. Participants stated that they learnt how "to use the machines", "to do physical exercise”, "stretchings", "to 
control their walking rhythm and heart-rate", and "what the exercises are for and which muscles are working”... The acquisition of this knowledge, over time, allowed the participants to perceive themselves as able enough to carry out the programmed sessions without supervision:

I know what I have to do for each machine, how to do it ... I first do the cardio ones, around six minutes in order to warm up, and then I do the ones to work out the strength. If one day I work out arms, the following I work out legs... (Telma's interview).

Participants also declared that they learnt to do different types of PA, getting a wider range of possibilities to keep an active lifestyle beyond the program:

You have taught us every kind of physical activity... I have being able to decide what I want to do because you have taught me ... On August it is very hot, so I am doing exercise in the water, because I have tried it and I know what it is. You have even taught us how to do exercise by ourselves without going to the gym. I mean, you have shown us several possibilities (Pam’s interview).

As we can appreciate, both circumstances above promote autonomy through the feelings of choice about what types of activity they engaged in outside of the program, as well as competence through the perception that they can effectively perform the chosen activities. In this sense, literature (Silva et al., 2010a; Teixeira et al., 2012b) suggests that when individuals following healthy behavioral goals feel both competent and autonomous, their efforts are more likely to result in long-lasting behavior changes. Perceived improvements in physical fitness and pain reduction. Despite being morbidly obese prior to surgery and feeling weak following their operation, participants reported many physical improvements with their participation in the PA program: 
Lucy: ... since I started the program nothing is the same, I feel better, more strength, more agility (Director’s research diary).

Participants pointed out that these improvements raised their capacity to perform and to overcome duties and activities easier, in and out of the program:

... before, ten minutes running on the treadmill and I went messed up. But now, ten minutes on the treadmill is nothing (Andrew’s interview).

... I stand the work better... The same things I did before, now I do them easier. That encourages you, it encourages you a lot (Ronda's interview).

These improvements in physical fitness can satisfy patients' need for competence, as participants' perceptions of progress constitute a powerful positive feedback that signify effectance (a participant literally comments: "You have shown me I am able", Lucy, Director's research diary), and promotes internalization of the value of the PA outcomes (health, optimal functioning, and quality of life), fostering identification and exercise participation (Teixeira et al., 2012a).

Moreover, most of the participants declared that the PA program reduced their chronic pain in arms, legs and, mainly, knees. One participant pointed out that he quit consuming medicines: "Now I don't take any pill and I endure physically (Andrew, Director's research diary). These health improvements also had a positive influence on their perception of competence:

When I started to do this exercise with the legs, my knees hurt a lot and I complained a lot. I didn’t finish it. But now I finish and my knee doesn’t hurt so much (Emily’s interview).

These effects of the PA program could have a positive influence on the adherence to exercise, not only through the mediation effect of competence on autonomous 
motivation, but through the reduction of bodily pain and physical limitations (Zabatiero et al., 2016).

Perceived social support and affection. All the participants highlighted the good relationships they had maintained in the PA program and the continuous support and affection that they received from the group:

... during this process in which I have kept losing weight, I have had very much support from my program-mates... And the thing I needed the most... affection. I have received lots of affection (Emily’s interview).

Moreover, participants pointed out that their relationship with the instructors had been very good, as instructors always showed a very kind attitude and they were always disposed to listen and help. Instructors’ behavior fostered more than a professional relationship with the patients, who felt that the instructors worried about them:

... when you are living through this phase it is very important being treated like a person, not just like a number, like a name. We are persons after all, and you have truly shown me a lot of affection and... I have felt very well with you. Very well (Ronda's interview).

Feeling understood by people in the same situation. Depending on participant's comments, the program was an opportunity not only to participate in PA, but to do it with people in the same situation. A participant (Ronda's interview) refers to the group as “the surgery-group club”, and other (Lezly's interview) points out that “being with people with the same problem is rewarding... we have the same goal”. Participants found in the program the chance to share with more freedom and confidence their feelings and experiences regarding the same problems: 
Lucy: "It's a group of people with the same situation, we talk about the same problems: food, if we have vomited... Even Andrew asked us the other day if we were having problems to pee” (Director’s research diary).

Trust to talk about intimate thoughts or experiences. Participants trusted in the social group of the PA program, feeling secure to speak about themselves. As we have seen above, even the only male participant (Andrew) felt confident to speak with the other women about urinating. Such was the confidence they reached that they revealed intimate experiences and thoughts which they had not been able to speak about before, experiencing a great catharsis:

"I have told things which I had inside. I have come out of my shell about things I had never told. I have started up and I have gotten rid of things I had inside and they hurt me...” (Emily’s interview).

As can be seen through the last three subcategories, need for relatedness was clearly satisfied in the PA context where participants shared the same situation and goals, forged authentic friendships and felt appreciated, understood and confident in talking openly (Reis et al., 2000). In this sense, literature has showed that fitness and health professionals who behave with warmth and caring toward exercisers, promote optimal functioning, exercise autonomous motivation, and feelings of acceptance and integration within a group (Hancox et al., 2018).

\section{Exercise autonomous motivation}

The PA program contributed to the satisfaction of participant's BPN. Therefore, taking into account SDT, the perceptions of competence, autonomy and relatedness would mediate the effect of social factors on motivation and promote the increase of participant's autonomous motivation toward PA (Edmunds et al., 2007; Silva et al., 
2011; Silva et al., 2010b; Teixeira et al., 2012a). In some cases, this change was remarkable:

... now I do things willingly. Now it isn’t hard to come to exercise. Before I had to exercise or move compulsorily. What I'm doing now was inconceivable before, and now I have fun, I enjoy it (Andrew's interview).

This quotation reflects a change from external or introjected regulation (compulsory behavior) to intrinsic motivation (enjoyment) during the PA program. But social contexts that promote BPN satisfaction, not only foster intrinsically motivated behavior, but also the internalization of extrinsic motivation (Deci and Ryan, 2000; Silva et al., 2011; Silva et al., 2010b). In this respect, most of participants showed an identified regulation because they reported doing PA because it was good for their health (I had to have done more exercise before, because there are some benefits: elasticity, stamina... I come here to take care of myself, because it is beneficial for meAlice's interview). Moreover, it is noteworthy the comment of a participant who literally affirmed to be “integrally motivated” (Lezly, Director's research diary), so it seems she had integrated PA with other aspects of herself. This situation enhances fully internalized motivation, predicting greater PA persistence over time (Silva et al., 2011; Teixeira et al., 2012a).

Consequences

According to participant's comments, the satisfaction of their BPN and exercise autonomous motivation in the PA program were associated with positive consequences, both at the contextual (PA) and global levels (general life).

Experience of fun. All the participants recognized experiencing great fun and enjoyment during the PA program: 
... we have lots of fun, there are many jokes, partying... I don't know... I enjoy it a lot (Alice’s interview).

I like to come to do the games. Oh yes, Wednesday! I was wishing the Wednesday to come here to do the games. Swimming or doing anything on Wednesday... I like it, now I am enjoying... I enjoy it (Emily's interview) [It seems noteworthy to point out that the games and novel physical activities were developed on Wednesday to escape from normal routines].

Different studies (e.g., Moreno et al., 2008; Vallerand, 2007) have found that satisfaction of BPN and intrinsic motivation are positively related to enjoyment in PA programs.

Physical activity involvement and intention to become physically active. Most of the participants stated that the program promoted the incorporation of PA into their lifestyle. For instance, a participant defined herself as "bike-addicted", and another participant declared “when I don't go for a walk, I miss something”. Moreover, all the participants reported that they wanted to keep doing any kind of PA after the program, either organized activities or on their own:

Emily: "When I finish the program I am going to keep walking, playing with the Wii console, and I would like to go cycling...” (Director’s research diary).

... I am thinking about to come here [to the gym] in September. I am considering I would like to continue (Lucy’s interview).

In this regard, literature has consistently found that need-supportive contexts lead to autonomous forms of exercise motivation and promote adherence and PA participation in populations with weight problems (Donnachie et al., 2017; Silva et al., 2010a; Silva et al., 2010b; Teixeira et al., 2012a). 
Body image improvements. Some participants confessed that, as a consequence of surgery and losing so much weight in a brief period of time, they started to have "flaccidity", "softness" and "folds of sagging skin" in different parts of their bodies. This situation caused them concern and made them think about having surgery to remove their skin folds (Jiménez-Loaisa et al., 2015; Sarwer et al., 2008; van Hout et al., 2006). However, they also emphasized that the PA program, apart from "accelerating more the weight loss" (Lezly's interview), also helped them to regain muscle tone, look more defined and reduce the skin folds:

Lezly: I notice muscle regaining, reduction of flaccid skin... I don’t notice skins in the face or abdomen, and I'm not getting surgery to remove them because I've perceived improvements with the exercise (Director's research diary). Thus, apart from the manifested concerns with skin folds, body image improvement might be promoted, not only because of the weight loss derived from surgery (Jiménez-Loaisa et al., 2015), but also because of the PA program grounded in SDT. In fact, Pearson and Hall (2013) found significant relationships between appearance-related body image and the more autonomous forms of exercise motivation among overweight and obese women.

Improvements in perceived happiness and self-confidence. Participants also believed that their participation in the PA program improved their mood and made them feel happier:

\footnotetext{
“In my house they have noticed... I'm glad, I'm happy and my husband tells me: when you come back from the gym you are radiant” (Pam, Director’s research diary).
} 
Likewise, participants also reported that they felt better about themselves and more self-confident. This allowed them to deal more effectively with everyday life situations:

... I could not wear a swimsuit, it cost me horrors. And now I wear a swimsuit every day, what can I say. The truth is that it gives me more confidence. We see that we are not alone in the world, there are more people who support us and that gives us more courage (Ronda's interview).

As we can see through the last two subcategories, BPN satisfaction in the PA program (contextual level) could likely have a positive bottom-up effect in the participants’ daily life (global level) (Vallerand, 2007), promoting these positive consequences and others such as vitality, psychological health, life satisfaction and well-being (Edmunds et al., 2007; Martín-Albo et al., 2012; Reis et al., 2000; Ryan and Deci, 2017; Teixeira et al., 2012a):

“I feel much better. I didn’t remember I could live in this fantastic way” (Pam’s interview).

In my whole life I hadn’t felt as well as now (Andrew’s interview).

In this line, several studies (see Jiménez-Loaisa et al., 2015 for a review) showed that postoperative increases in PA following bariatric surgery were associated not only with greater weight loss, but with greater improvements in general health, vitality and mental health.

Attitude improvement for a better social life. Regarding the possible improvements in participants' well-being described above, literature indicates that emotional well-being is reliably related to several personality traits, including selfesteem, perceived personal control, optimism and extraversion (Myers and Diener, 
1995). In this sense, participants indicated that there also was a change in their focus about personal relationships from avoiding to enjoying and even looking for them:

... I feel more secure. I feel more sociable. I like to be more with people (Lucy’s interview).

... I was like a little isolated. My friends would call me for a coffee and I wouldn't go ... I always had an excuse. And now they call me to meet and before hanging up the phone I'm on the street (Ronda's interview).

This improvement in extraversion could be another success of the program, as it is mediated by intrinsic and extrinsic behavioral regulations (e.g., fun and looking fit respectively), and it is positively related to exercise participation (Lewis \& Sutton, 2011), and associated to subjective well-being (Li et al., 2015).

\section{Conclusions and limitations}

The present study analyzed the perceived psychological and social effects of a PA program in bariatric patients from a SDT perspective. The information gleaned could be useful in developing future PA programs with the objective of satisfying patients' BPN, developing more autonomous motivation toward PA and achieving higher health-related quality of life.

To foster autonomy, health care professionals should adopt strategies like acting democratically and positively at any moment, as well as taking patients’ opinions and suggestions into account. To promote competence, professionals should help participants to develop realistic short and long term goals, which allow them be aware of their progress and improvements. Knowledge acquisition about techniques, methods and types of PA should be an aim of any program, not only to reach autonomous exercisers, in and out the program, but to let them feel competent about the acquisition of new skills. To promote relatedness, professionals should treat patients with closeness, 
understanding and affectivity, and promote warm, close and supporting relationships between the group participants.

Although the present study provides insights into the bariatric patients' perceptions of the motivational effects of a PA program based on SDT, the design does not allow us to infer causal relationships. Moreover, it would have been interesting to interview the program instructors to have another point of view of the effectiveness of the intervention. Likewise, the inclusion of an interview with the patients at the midpoint of the PA program could have provided useful information to adjust some strategies and to introduce others with the objective to improve the quality of the intervention.

Another limitation that we must acknowledge is that the present study did not include a follow-up intervention to facilitate patients' active lifestyle after the PA program. In fact, many patients returned to a sedentary lifestyle one year after the end of the study. During the PA program, they lived in a "bubble” in which they perceived social support from people in their same situation and from exercise professionals. However, after that, it is likely that they had difficulties accessing similar PA programs, adapted to their characteristics and needs. The process after bariatric surgery is hard and there are many factors which can hinder long-term behavior maintenance. Weight regains, physical problems, concerns about skin folds, and other psychosocial issues (Jiménez-Loaisa et al., 2015) could cause relapse into a sedentary lifestyle. Future studies should analyze the factors which support or hinder the long-term maintenance of an active lifestyle after SDT interventions to promote PA. More knowledge is necessary about strategies that can facilitate a positive transition from an exercise intervention to an active lifestyle post-intervention. 
In spite of these limitations, this study suggest that public investment in the development of PA programs, designed and supervised by qualified professionals to encourage the adoption of PA as a healthy behavior, is fundamental, not only for individuals undergoing bariatric surgery, but also for the general population. 


\section{References}

Bazeley P and Jackson K (2013) Qualitative Data Analysis with NVivo. London: Sage. Bond DS, Phelan S, Wolfe LG, et al. (2008) Becoming physically active after bariatric surgery is associated with improved weight loss and health-related quality of life. Obesity 17(1): 78-83.

Deci EL and Ryan RM (2000) The “what” and “why” of goal pursuits: Human needs and the self-determination of behaviour. Psychological Inquiry 11(4): 227-268.

Donnachie C, Wyke S, Mutrie N, et al. (2017) 'It’s like a personal motivator that you carried around wi' you': utilising self-determination theory to understand men's experiences of using pedometers to increase physical activity in a weight management programme. International Journal of Behavioral Nutrition and Physical Activity 14: 61. DOI: 10.1186/s12966-017-0505-z

Edmunds J, Ntoumanis N and Duda J (2007) Adherence and well-being in overweight and obese patients referred to an exercise on prescription scheme: A selfdetermination theory perspective. Psychology of Sport and Exercise 8(5): 722740.

Elkins G, Whitfield P, Marcus J, et al. (2005) Noncompliance with behavioral recommendations following bariatric surgery. Obesity Surgery 15(4): 546-551.

Forbush SW, Nof L, Echternach J, et al. (2011) Influence of activity on quality of life scores after RYGBP. Obesity Surgery 21(8): 1296-1304.

Fortier MS, Duda JL, Guerin E, et al. (2012) Promoting physical activity: development and testing of self-determination theory-based interventions. International Journal of Behavioral Nutrition and Physical Activity 9: 20. DOI: 10.1186/1479-5868-920 
Hancox J, Quested E, Thøgersen-Ntoumani C, et al. (2018) Putting self determination theory into practice: application of adaptive motivational principles in the exercise domain. Qualitative Research in Sport, Exercise and Health 10(1): 75-91.

Hsieh H and Shannon SE (2005) Three approaches to qualitative content analysis. Qualitative Health Research 15(9): 1277-1288.

Jacobi D, Ciangura C, Covet C, et al. (2011) Physical activity and weight loss following bariatric surgery. Obesity 12(5): 366-377.

Jiménez-Loaisa A, Beltrán-Carrillo VJ, González-Cutre D, et al. (2015) Psychosocial effects of surgery and physical activity in bariatric patients: A systematic review. European Journal of Human Movement 35: 12-33.

Kinnafick FE, Thøgersen-Ntoumani C and Duda JL (2014) Physical activity adoption to adherence, lapse, and dropout: A self-determination theory perspective. Qualitative Health Research 24(5): 706-718.

Lee M, Kim MJ, Suh D, et al. (2016) Feasibility of a self-determination theory-based exercise program in community-dwelling South Korean older adults: Experiences from a 13-month trial. Journal of Aging and Physical Activity 24(1): 8-21.

Leenknecht MJM, Wijnia L, Loyens SMM, et al. (2017). Need-supportive teaching in higher education: Configurations of autonomy support, structure, and involvement. Teaching and Teacher Education 68: 134-142.

Lewis M and Sutton A (2011) Understanding exercise behavior: examining the interaction of exercise motivation and personality in predicting exercise frequency. Journal of Sport Behavior 34(1): 82-97.

Li Y, Lan J and Ju C (2015) Self-esteem, gender and the relationship between extraversion and subjective well-being. Social Behavior and Personality 43(8): 1243-1254. 
Livhits M, Mercado C, Yermilov I, et al. (2010) Exercise following bariatric surgery: systematic review. Obesity Surgery 20(5): 657-665.

Magro DO, Genoleze B, Delfini R, et al. (2008) Long-term weight regain after gastric bypass: A 5-year prospective study. Obesity Surgery 18(6): 648-651.

Martín-Albo J, Núñez J, Domínguez E, et al. (2012) Relationships between intrinsic motivation, physical self-concept and satisfaction with life: A longitudinal study. Journal of Sport Sciences 30(4): 337-347.

Moreno JA, López de San Román M, Martínez Galindo C, et al. (2008) Peers’ influence on exercise enjoyment: A self-determination theory approach. Journal of Sports Science and Medicine 7(1): 23-31.

Moya, M., Hernández, A., Sarabia, J. M., et al. (2014) Bariatric surgery, weight loss and the role of physical activity: a systematic review. European Journal of Human Movement 32: 145-160.

Myers DG and Diener E (1995) Who is happy? Psychological Science 6(1): 10-19.

Ntoumanis N, Quested E, Reeve J, et al. (2017) Need supportive communication: Implications for motivation in sport, exercise, and physical activity. In: Jackson B, Dimmock JA and Compton J (eds) Persuasion and Communication in Sport, Exercise, and Physical Activity. Abingdon, UK: Routledge, pp. 155-169.

Peacock CP and Zizzi SJ (2011) An assessment of patient behavioral requirements preand post-surgery at accredited weight loss surgical centers. Obesity Surgery 21(12): 1950-1957.

Pearson ES and Hall CR (2013) Examining body image and its relationship to exercise motivation: an 18-week cardiovascular program for female initiates with overweight and obesity. Baltic Journal of Health and Physical Activity 5(2): 121131. 
Reis HT, Sheldon KM, Gable SL, et al. (2000) Daily well-being: The role of autonomy, competence, and relatedness. Personality and Social Psychology Bulletin 26(4): 419-435.

Rosenberger PH, Henderson KE, White MA, et al. (2011) Physical activity in gastric bypass patients: associations with weight loss and psychosocial functioning at 12month follow-up. Obesity Surgery 21(10): 1564-1569.

Ryan RM and Deci EL (2017) Self-Determination Theory: Basic Psychological Needs in Motivation, Development, and Wellness. New York: Guilford Press.

Sarwer DB, Fabricatore AN, Jones-Corneille LR, et al. (2008) Psychological issues following bariatric surgery. Primary Psychiatry 15(8): 50-55.

Sebire SJ, Edwards MJ, Fox KR, et al. (2016a) Delivery and receipt of a selfdetermination-theory-based extracurricular physical activity intervention: Exploring theoretical fidelity in action 3:30. Journal of Sport \& Exercise Psychology 38(4): 381-395.

Sebire SJ, Kesten JM, Edwards MJ, et al. (2016b) Using self-determination theory to promote adolescent girls' physical activity: Exploring the theoretical fidelity of the Bristol Girls Dance Project. Psychology of Sport and Exercise 24: 100-110.

Shenton AK (2004) Strategies for ensuring trustworthiness in qualitative research projects. Education for Information 22(2): 63-75.

Silva MN, Markland D, Carraça EV, et al. (2011) Exercise autonomous motivation predicts 3-year weight loss in women. Medicine and Science in Sports and Exercise 43(4): 728-737.

Silva MN, Markland DM, Vieira PN, et al. (2010a) Helping overweight women become more active: Need support and motivational regulations for different forms of physical activity. Psychology of Sport and Exercise 11(6): 591-601. 
Silva MN, Vieira PN, Coutinho SR, et al. (2010b) Using self-determination theory to promote physical activity and weight control: a randomized controlled trial in women. Journal of Behavioral Medicine 33(2): 110-122.

Sirtori A, Brunani A, Villa V, et al. (2012) Obesity is a marker of reduction in QoL and disability. The Scientific World Journal 2012: 1-6. DOI: 10.1100/2012/167520

Teixeira PJ, Carraça EV, Markland D, et al. (2012a) Exercise, physical activity, and self-determination theory: a systematic review. International Journal of Behavioral Nutrition and Physical Activity 9: 78. DOI: 10.1186/1479-5868-9-78

Teixeira PJ, Silva MN, Mata J, et al. (2012b) Motivation, self-determination, and longterm weight control. International Journal of Behavioral Nutrition and Physical Activity 9: 22. DOI: 10.1186/1479-5868-9-22

Thøgersen-Ntoumani C, Ntoumanis N, Uren H, et al. (2017) Perceptions of group-based walks and strategies to inform the development of an intervention in retirement villages: Perspectives of residents and village managers. Journal of Physical Activity and Health 25(2): 261-268.

Vallerand RJ (2007) Intrinsic and extrinsic motivation in sport and physical activity. A review and a look at the future. In: Tenenbaum G and Eklund RC (eds) Handbook of Sport Psychology. 3rd ed. New York: John Wiley, pp.59-83.

van Hout GC, Boekestein P, Fortuin FA, et al. (2006) Psychosocial functioning following bariatric surgery. Obesity Surgery 16(6): 787-794.

Wilson P, Mack D and Grattan K (2008) Understanding motivation for exercise: A selfdetermination theory perspective. Canadian Psychology 49(3): 250-256.

World Health Organization. (2017). Obesity and overweight (Fact sheet No. 311). Available at: http://www.who.int/mediacentre/factsheets/fs311/en/ 
Zabatiero J, Hill K, Gucciardi DF, et al. (2016) Beliefs, barriers and facilitators to physical activity in bariatric surgery candidates. Obesity Surgery 26(5): 10971109. 
Table 1. The Effects of a Physical Activity Program, grounded in Self-Determination

Theory, on Post-Bariatric Surgery Patients

\begin{tabular}{ll}
\hline Categories & Subcategories \\
$\begin{array}{l}\text { Physical activity program } \\
\text { chatacteristics and BPN }\end{array}$ & Caring about their opinion and preferences. \\
& $\begin{array}{l}\text { Instructors with a democratic and positive } \\
\text { disposition. }\end{array}$ \\
& $\begin{array}{l}\text { Acquiring knowledge for being autonomous } \\
\text { exercisers. }\end{array}$ \\
& $\begin{array}{l}\text { Perceived improvements in physical fitness and pain } \\
\text { reduction. }\end{array}$ \\
& Perceived social support and affection. \\
& Feeling understood by people in the same situation. \\
& Trust to talk about intimate thoughts or experiences. \\
& \\
Exercise autonomous & Attitude improvement for a better social life. \\
motivation & Body image improvements. \\
Consequences & Physical activity involvement and intention to \\
&
\end{tabular}

